\title{
Electrophysiological properties of rat nodose ganglion neurons co-transplanted with carotid bodies into the chick chorioallantoic membrane
}

\author{
JAIME EUGENÍN ${ }^{1}$ and CARLOS EYZAGUIRRE ${ }^{2}$
}

1. Laboratory of Neural Systems, Department of Biology, Universidad de Santiago de Chile, Santiago, Chile, 2. Department of Physiology, University of Utah School of Medicine, Salt Lake City, Utah, USA

\begin{abstract}
The electrophysiological properties of nodose ganglion neurons were evaluated immediately after removing nodose ganglia from young adult rats and 3 to 10 days after nodose ganglia implantation -either alone or coimplanted with carotid bodies- onto the chick chorioallantoic membrane. Implanted and co-implanted nodose neurons were less excitable than acutely recorded nodose neurons. Co-implanted neurons also showed reduced amplitudes for both action potentials and spike after-hyperpolarizations relative to those found in acutely recorded nodose ganglion neurons and a smaller time constant $(\tau)$ than that found in implanted neurons. In addition, no spontaneous activity was recorded from nodose ganglion neurons co-implanted with carotid bodies during 3-9 days, which suggests that functional synapses between carotid glomus cells and nodose neurons were not yet established. Results indicate the feasibility of obtaining viable nodose neurons for up to 10 days grafted onto the chick chorioallantoic membrane, where they can conserve most of their passive and active membrane properties and also are susceptible to carotid bodies trophic influences. They also suggest that nodose neurons would need more time for the development of functional synapses when grafted with carotid body glomus cells.
\end{abstract}

Key terms: arterial chemoreceptors, synaptogenesis, transplantation, trophism.

\section{INTRODUCTION}

The carotid body, a tiny organ situated in the bifurcation of the carotid artery, senses $\mathrm{PO}_{2}$, $\mathrm{PCO}_{2}$, and $\mathrm{pH}$ in peripheral arterial blood (Eyzaguirre et al., 1983). The chemoreceptor function of the carotid body depends on the glomus (type I cells) and the carotid nerve sensory fibers that innervate them (Eyzaguirre and Zapata, 1984). As a result of glomus cell activation and complex synaptic interactions, hypoxia (López-Barneo et al., 2004), hypercarbia or acidosis increase the carotid nerve afferent impulses and trigger respiratory and cardiovascular reflexes (Eyzaguirre et al., 1983).

As indicated in a companion paper by Zapata and Larraín (2005), different experimental approaches have been used to try to reveal the synaptic events between glomus and sensory cells from the side of the nerve terminals. Because the nerve terminals are branched and very small, recording of synaptic or generator potentials directly from the tissue is technically difficult (Hayashida et al., 1980), even in slices of carotid bodies (Pardal and López-Barneo, 2002). Another strategy has been to appose closely glomus cells and somata of sensory fibers looking for the establishment of synapses closer to the soma; this can be obtained by coculturing dissociated sensory neurons with fragments of carotid body (Goldman et al., 1987) or with dissociated glomus cells (Alcayaga and Eyzaguirre, 1990; Nurse and

Corresponding author: Dr. Jaime Eugenín, MD, PhD, Laboratory of Neural Systems, Department of Biology, Universidad de Santiago de Chile, Casilla 40, Correo 33, Santiago 1, Santiago, Chile, Tel: (56-2) 681-2575, Fax: (56-2) 681-2108, Email: jeugenin@1auca.usach.cl 
Zhang, 2001). In these preparations, the electrotonic spread distance between a synaptic site and soma is shortened artificially, which, theoretically, would increase the chances to detect local synaptic electrical events through microelectrode impalement from the somata of sensory fibers. However, problems with these in vitro approaches -like cell dedifferentiation, alteration of tissue structure, or perturbation of cell interactions- may be important factors when interpreting results.

An alternative method to primary tissue cultures of dissociated cells is provided by the choriallantoic membrane of 6- to 12-day chick embryos, which is able to support the growth and survival of tumors and grafts of embryonic and adult tissues (Coulombre, 1967; Hamburger, 1960). This method, introduced by Rous and Murphy in 1911 (Rous and Murphy, 1911), makes use of the high capacity of the chorioallantoic mesenchyma for responding to the presence of exogenous tissue with proliferation (Coulombre, 1967, Hamburger, 1960) and neoangiogenesis (Lemus et al., 2001), which favors a fast incorporation and vascularization of the grafts. In a previous work, it was described that carotid bodies and nodose ganglia from young adult rats were incorporated into the chorioallantoic membrane, vascularized, and maintained alive for up to 12 days, showing preservation of their general morphological characteristics (Gual et al., 1991). Moreover, regenerating fibers originated from nodose ganglion explants invade carotid body grafts and closely contacted glomus cells showing features of immature synapses (Gual et al., 1991). In the present paper, to know whether transplanted nodose ganglion neurons largely conserve their electrophysiological properties and to address whether characteristics of nodose neurons can be modified by trophic interactions with their target organ, we compared the passive and active properties of neurons recorded from nodose ganglia in vitro with those of nodose ganglion neurons implanted alone or co-implanted with carotid bodies onto the chick chorioallantoic membrane.

\section{METHODS}

Experiments were done in accord with the Institute for Laboratory Animal Research (ILAR) Guide for the Care and Use of Laboratory Animals. Eighty male SpragueDawley rats (100-150g, Charles River Laboratories, Inc.) were anesthetized with sodium pentobarbital (60 $\mathrm{mg} \mathrm{Kg}^{-1}$ i.p.). The carotid bodies and nodose ganglia were aseptically removed, their capsular connective tissue eliminated, and both immersed into ice-cold Hank's solution without $\mathrm{Ca}^{+2}$ and $\mathrm{Mg}^{+2}$.

Sixty fertilized white Leghorn chicken eggs were maintained in a forced-air incubator at $38.0 \pm 0.5{ }^{\circ} \mathrm{C}$ and $60-70 \%$ of humidity and rotated daily. The day before implantation a hole was made into the egg air chamber to detach the chorioallantoic membrane from the inner surface of the shell. On implantation day, a square of shell (5 mm each side) was removed and the shell membrane was cut using fine scissors (Fig 1A). The site of implantation was chosen near the bifurcation of a large choriallantoic artery and prepared by removing the thin chorion layer by abrasion with fine forceps; then the grafts were transferred within a pipette containing Hank's solution, allocated onto the choriallantoic membrane, and positioned next to each other. Hank's solution in excess was removed by blotting, the shell window was covered with the shell square, and the borders were sealed with paraffin wax. In some cases, a glass coverslip or parafilm was used to cover the shell window.

After 3 to 9 days, a portion of the choriallantoic membrane containing the grafts was transferred and fixed with insect pins to the Sylgard bottom of a chamber of $2 \mathrm{ml}$ in volume, mounted on the stage of a phase-contrast microscope. The preparation was superfused with 1-2 $\mathrm{ml} \mathrm{min}^{-1}$ of Earle's balanced saline containing $26 \mathrm{mM}$ $\mathrm{NaHCO}_{3}$, gassed with $95 \% \mathrm{O}_{2}$ and $5 \% \mathrm{CO}_{2}$ (pH 7.37-7.40), and maintained at $30^{\circ} \mathrm{C}$ by sensing the fluid chamber temperature with a thermistor probe and heating the fluid with a heat resistance commanded by a heat controller. 


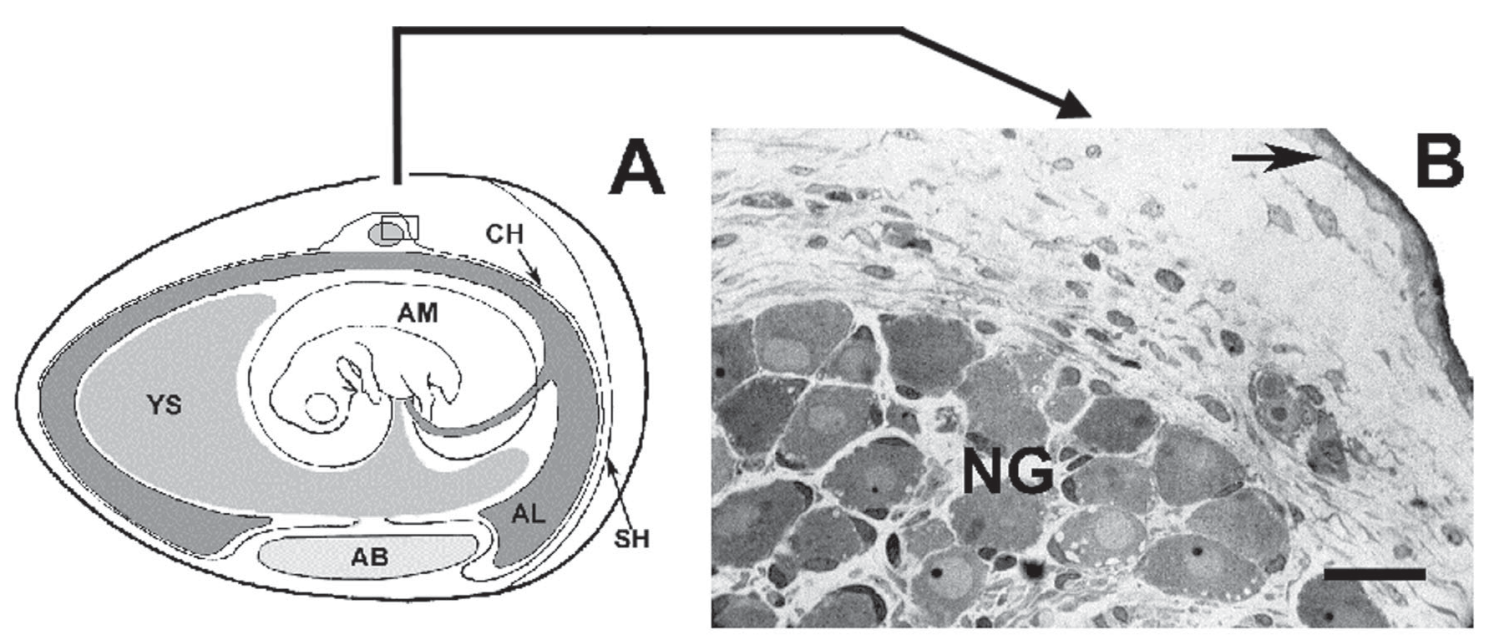

Figure 1: A. Scheme of chorioallantoic grafting. Exogenous tissue was introduced through a window in the shell and was incorporated by the chorioallantoic membrane $(\mathrm{CH})$. AB, albumen; AL, allantoic cavity; AM, amniotic cavity; SH, shell membrane; YS, yolk sac.

B. Light microscopy showing a nodose ganglion (NG) incorporated into the mesenchyma of the chorioallantoic membrane after 6 days of implant. Arrow indicates the chorionic epithelium; Bar $=$ $15 \mu \mathrm{m}$.

Intracellular recordings were done with borosilicate glass microelectrodes of 60-80 $\mathrm{M} \Omega$ filled with KAc $3 \mathrm{M}$ and connected to a voltage follower amplifier via a bridge circuit. The microelectrode was advanced in steps of $1 \mu \mathrm{m}$ through the tissue with a piezoelectric drive mounted on a 3-axis manipulator.

Neurons lacking membrane resting potential of $-40 \mathrm{mV}$ or lower or having electrical-induced action potentials without overshoot were discarded from analysis. Neurons were stimulated with a series of hyperpolarizing electrical pulses of $100 \mathrm{~ms}$ of duration, followed by a series of depolarizing electrical pulses starting in 1 $\mathrm{ms} \times 0.1 \mathrm{nA}$; after defining threshold values, step long-duration (50-200 ms) depolarizations were performed to determine neurons ability for firing repetitively. Membrane potentials were stored on FM tape (DC to $2.5 \mathrm{KHz}$ ), and signals were digitized using an analog-todigital converter with sampling rate of 38 $\mathrm{KHz}$ and analyzed using custom-developed programs. To discard that changes in electrophysiological properties may due to an effect of population selection, neurons were compared after being classified as C- or A-type. Since action potential duration of nodose ganglion neurons is strongly correlated with the conduction velocity, neurons exhibiting $\mathrm{APd}_{66 \%}$ (action potential duration at the point of $66 \%$ height of action potential) broader than $2 \mathrm{~ms}$ were classified as C-type ( $\mathrm{Li}$ and Schild, 2002, Schild et al., 1994). Neurons presenting $\mathrm{APd}_{66 \%}$ below $2 \mathrm{~ms}$ were classified as $\mathrm{A}$ type.

Morphological study was done by immersing the grafts into $2 \%$ paraformaldehyde, $2 \%$ glutaraldehyde in $0.1 \mathrm{M}$ cacodylate buffer containing $0.9 \mathrm{mM}$ $\mathrm{CaCl}_{2}$ during 2 hours, washed in $8 \%$ buffered sucrose, and postfixing in $2 \%$ $\mathrm{OsO}_{4}$ by overnight; then they were washed in $2.5 \% \mathrm{NaCl}(\mathrm{pH} 7.6)$, dehydrated in ethanol followed by acetone, and embedded in Araldite (Fluka); semithin sections for light microscopy were stained with methylene blue.

All data were expressed as arithmetic mean \pm SEM. Statistical analysis was done using one-way ANOVA followed by the post hoc Dunn's (Bonferroni) test for comparisons between experimental conditions; $\mathrm{P}<0.05$ was used as the level of statistical significance. 


\section{RESULTS}

Parenchyma of nodose ganglia and carotid bodies appeared normal in most of the superficial areas of implants and coimplants (Fig 1B); however, deep or central areas of nodose ganglia had fewer neurons and show different stages of cell necrosis. Thus, "healthy neurons" (exhibiting resting membrane potential of $-40 \mathrm{mV}$ or lower and action potentials with overshoot) were found more often in recordings done immediately after removing the nodose ganglia than in recordings from implants or co-implants performed after 3 to 9 days.

All "healthy neurons" recorded from the three experimental conditions showed a relatively stable resting membrane potential. No spontaneous membrane potential oscillations or action potentials were observed in the three conditions. The total number of recorded A-type and C-type neurons followed grossly the population distribution reported in previous investigations (Li and Schild, 2002; Schild et al., 1994); that is, most of the cells (8090\%) showed C-type (unmyelinated) fiber characteristics. As expected, C-type neurons fired only once or twice, but not repetitively in response to step longdepolarizations; they exhibited relative wider action potentials with slower upstroke and downstroke velocities and longer-lasting after-hyperpolarizations than those observed in A-type (myelinated) fibers (Table I).

TABLE I

Passive and active membrane properties of nodose ganglion cells in vitro, implanted alone and co-implanted with carotid bodies onto the chick embryo chorioallantois.

\begin{tabular}{|c|c|c|c|c|c|c|}
\hline & \multicolumn{3}{|c|}{ C-type nodose neurons } & \multicolumn{3}{|c|}{ A-type nodose neurons } \\
\hline & in vitro & implanted & co-implanted & in vitro & implanted & co-implanted \\
\hline $\mathrm{MP}(\mathrm{mV})$ & $-56.4 \pm 2.5(42)$ & $-55.4 \pm 1.9(23)$ & $-47.9 \pm 1.6(17)$ & $-60.6 \pm 4.3(12)$ & $-48.0 \pm 4.7(4)$ & $-51(2)$ \\
\hline $\mathrm{R}_{\mathrm{o}}(\mathrm{M} \Omega)$ & $84.4 \pm 39.0(42)$ & $74.1 \pm 11.1(23)$ & $40.1 \pm 7.6(13)$ & $48.5 \pm 15.5(12)$ & $69.7 \pm 25.1(4)$ & $17.6(2)$ \\
\hline $\mathrm{C}_{\mathrm{o}}(\mathrm{pF})$ & $75.3 \pm 7.4(42)$ & $65.1 \pm 11.9(23)$ & $59.2 \pm 15.2(13)$ & $86.6 \pm 14.6(12)$ & $71.7 \pm 28.2(4)$ & $197(2)$ \\
\hline$\tau(\mathrm{ms})$ & $2.9 \pm 0.3(42)$ & $3.7 * 3 \pm 0.4(23)$ & $1.7 * 2 \pm 0.3(13)$ & $2.8 \pm 0.4(12)$ & $3.1 \pm 0.4(4)$ & $3.0(2)$ \\
\hline $\mathrm{APa}(\mathrm{mV})$ & $85.2 * * 3 \pm 3.6(42)$ & $76.4 \pm 3.6(23)$ & $65.6^{* * 1} \pm 2.1(17)$ & $89.8 \pm 5.9(12)$ & $56(1)$ & $56(2)$ \\
\hline $\operatorname{APd}_{66 \%}(\mathrm{~ms})$ & $3.3 \pm 0.1(42)$ & $4.1 \pm 0.3(23)$ & $3.8 \pm 0.6(17)$ & $1.6 \pm 0.06(12)$ & $1.7(1)$ & $1.6(2)$ \\
\hline APov $(\mathrm{mV})$ & $28.8 * 3 \pm 2.2(42)$ & $20.6 \pm 2.5(23)$ & $17.5^{* 1} \pm 2.0(17)$ & $28.1 \pm 3.3(12)$ & $8(1)$ & $5(2)$ \\
\hline $\mathrm{Uv}\left(\mathrm{V} \mathrm{s}^{-1}\right)$ & $44.5 \pm 3.4(26)$ & $44.5 \pm 6.2(16)$ & $40.4 \pm 8.1(14)$ & $101.6 \pm 15.7(9)$ & $112(1)$ & $98(2)$ \\
\hline $\mathrm{Dv}\left(\mathrm{V} \mathrm{s}^{-1}\right)$ & $-38.5 \pm 3.0(26)$ & $-39.3 \pm 6.2(16)$ & $-32.8 \pm 4.0(14)$ & $-77.1 \pm 6.3(9)$ & $-67(1)$ & $-66(2)$ \\
\hline Thv (mV) & $20.3^{* 2,3} \pm 1.3(26)$ & $31.3 * 1 \pm 3.3(16)$ & $30.5 * 1 \pm 3.5(15)$ & $28.0 \pm 5.1(9)$ & $25(1)$ & $23(2)$ \\
\hline ThI (nA) & $1.1 \pm 0.1(26)$ & $2.5 \pm 1.6(16)$ & $1.3 \pm 0.4(15)$ & $1.6 \pm 0.3(9)$ & $2.0(1)$ & $1.3(2)$ \\
\hline ThD (ms) & $1.6^{* * 2} \pm 0.1(26)$ & $2.7 * * 1 \pm 0.4(16)$ & $2.4 \pm 0.2(15)$ & $1.6 \pm 0.3(9)$ & $2.1(1)$ & $1.8(2)$ \\
\hline $\mathrm{AHPa}(\mathrm{mV})$ & $16.2 * 3 \pm 1.0(33)$ & $15.1 \pm 2.1(21)$ & $9.3 * 1 \pm 1.2(16)$ & $14.9 \pm 3.0(11)$ & - & -- \\
\hline AHPd (ms) & $46.7 \pm 9.0(33)$ & $46.1 \pm 11.2(21)$ & $31.2 \pm 5.3(16)$ & $18.2 \pm 3.5(11)$ & - & - \\
\hline
\end{tabular}

$\mathrm{AHPa}$ and $\mathrm{AHPd}=$ amplitude and duration of action potential after-hyperpolarization; $\mathrm{APa}=$ amplitude of action potential; $\mathrm{APd}_{66 \%}=$ action potential duration at the point of $66 \%$ height of $\mathrm{AP} ; \mathrm{APov}=$ overshoot; $\mathrm{C}_{0}=$ membrane capacitance; $\mathrm{Dv}=$ average downstroke velocity; $\mathrm{MP}=$ resting membrane potential; $\mathrm{R}_{0}=$ membrane resistance; $\mathrm{ThD}=$ threshold duration of electrical pulse; $\mathrm{ThI}=$ threshold intensity of electrical pulse; Thv $=$ threshold depolarization; $\tau=$ membrane time constant. ${ }^{* n}$ or $* * n, P<0.01$ and $\mathrm{P}<0.001$ in Dunn's (Bonferroni) test respect to $\mathrm{n}^{\text {th }}$ group; values are expressed in arithmetic mean \pm SEM. (n) corresponds to the number of cells studied. 
Since very few A-type neurons could be recorded from implanted or co-implanted nodose ganglia, comparisons between experimental conditions were possible only for C-type neurons. In general, the passive and active electrical properties of C-type nodose ganglion neurons for the three experimental conditions were close to the values previously reported in vitro ( $\mathrm{Li}$ and Schild, 2002, Schild et al., 1994). As illustrated in Table I, implanted nodose neurons were less excitable and required a higher voltage depolarization (Thv) and a longer electrical pulse (ThD) to trigger action potentials than those required by nodose neurons in vitro. Co-implanted neurons, in addition to require a higher depolarization to trigger action potentials, showed smaller action potentials (APa), overshoot (APov), and spike afterhyperpolarization (AHPa) than those observed in nodose neurons in vitro. Moreover, co-implanted neurons showed a smaller time constant $(\tau)$ than that in implanted neurons.

\section{DISCUSSION}

The present results confirm that the chick embryo choriallantoic membrane can sustain the growth of explanted rat nodose ganglia and carotid bodies. Both tissues are integrated by the mesenchyma of the chorioallantoic membrane making possible that microcirculations could be connected to the capillary network sustained by the circulatory system of the chick embryo. In the present paper, we show that nodose ganglion neurons not only conserve their morphology but also they can maintain most of their electrophysiological properties.

However, neurons implanted showed a reduction in excitability, requiring bigger and more prolonged depolarizations to induce action potentials. Co-implanted neurons also presented short action potentials with reduction of the overshoot. Further research will be required for revealing the underlying mechanisms, as for example, for determining whether the interaction with carotid body cells induces a change in the density of voltage-sensitive sodium channels in nodose neurons or sodium channels modify their intrinsic properties or there is a change in the expression of the types of sodium conductances (Schild and Kunze, 1997). On the other hand, it is not known whether the observed changes in electrical membrane properties are specific for carotid bodies co-implants or they can arise after coimplantation with other tissues. It is possible that the influence of carotid body grafts upon the nodose neurons properties depends on the culturing conditions, since in co-cultures of dissociated nodose ganglion neurons with glomus cells such modifications have not been described. In contrast, the reduction in the amplitude of the nodose neuron spike afterhyperpolarization in the co-implants may be related to the presence of carotid body cells, since in dissociated tissue cultures the presence of glomus cells also produced smaller and longer spike afterhyperpolarizations (Alcayaga and Eyzaguirre, 1990).

Regenerating axons from nodose neurons can contact glomus cells through morphologically immature synapses after 6 days of co-implantation (Gual et al., 1991). In the present work, absence of spontaneous electrical activity recorded from somata, even after 9 days of co-implantation, suggests that synapses between glomus cells and sensory neurons, if any, are few or not functional. Although, it was not explored systematically, hypoxic or acidic stimuli restricted onto the carotid body graft did not evoke changes in membrane potential of grafted nodose neurons. Since properties of carotid body cells are highly alterable by hypoxia (Del Río et al., 2004; Mosqueira et al., 2004), we cannot discard any deleterious effect derived from our experimental procedures affecting their capacity for interacting with nodose ganglion cells. On the other hand, it is possible that appropriate and functional synaptogenesis may require more time than the 7 to 10 days provided for this preparation (Coulombre, 1967). Reimplanting a carotid body-nodose ganglion graft onto another chick embryo 
chorioallantoic membrane may provide more room for development of functional synapses. On the other hand, unpublished results indicate that rat nodose neurons also survive and conserve electrical membrane properties after 5 days in the coelomic cavity. Then, alternatively, co-implants can be done into the coelomic cavity of chick embryos and be followed after several days of post-natal stages. Finally, use of petrosal ganglia, which contain neurons able to survive in dissociated culture (Valdés et al., 2004), may increase the chances of success in obtaining functional synapses between glomus cells and sensory fibers.

\section{ACKNOWLEDGEMENTS}

This work is dedicated to Dr. P. Zapata, a great scientist and mentor, who has contributed decisively in the formation of several generations of Chilean scientists. We thank the technical assistance of Mrs. Naida Stayner. The support of JE by a Fogarty International Research Fellowship (5F05TW04271-02) from the NIH and a Continuation Grant DICYT-USACH is acknowledged. CE was supported by $\mathrm{NIH}$ Grant NS 07938.

\section{REFERENCES}

ALCAYAGA J, EYZAGUIRRE C (1990) Electrophysiological evidence for the reconstitution of chemosensory units in co-cultures of carotid body and nodose ganglion neurons. Brain Res 534: 324-8

COULOMBRE AJ (1967) Grafting of Embryonic Rudiments. In: WILT FH \& WESSELS NK (eds) Methods in Developmental Biology. New York: Crowell. pp: 457-469

DEL RÍO R, REY S, ARIAS P, ALCAYAGA J, ITURRIAGA R (2004) Chronic intermittent hypoxia enhances chemosensory and ventilatory responses to acute hypoxia. Biol Res 37: R-90

EYZAGUIRRE C, FITZGERALD RS, LAHIRI S, ZAPATA P (1983) Arterial chemoreceptors. In: SHEPHERD JT \& ABBOUD FM (eds) American Physiological Society: Handbook of Physiology, sect. 2: The Cardiovascular System, vol. 3: Peripheral Circulation and Organ Blood Flow. Baltimore, MD: Williams \& Wilkins. pp: 557-621
EYZAGUIRRE C, ZAPATA P (1984) Perspectives in carotid body research. J Appl Physiol 57: 931-57

GALLEGO R, EYZAGUIRRE C (1978) Membrane and action potential characteristics of $\mathrm{A}$ and $\mathrm{C}$ nodose ganglion cells studied in whole ganglia and in tissue slices. J Neurophysiol 41(5): 1217-32

GOLDMAN WF, SATO M, STENSAAS LJ, EYZAGUIRRE C (1987) Acetylcholine- and dopamine-induced excitation of cultured newborn rabbit nodose ganglion neurons: Effects of co-culture with carotid body fragments. In: RIBEIRO JA \& PALLOT DJ (eds) Chemoreceptors in Respiratory Control. London: Croom Helm. pp: 284-295

GUAL A, EUGENÍN J, ALCAYAGA J, STENSAAS LJ, EYZAGUIRRE C (1991) The chick chorioallantoic membrane promotes survival of co-transplanted rat carotid bodies and nodose ganglia. Brain Res 556: 13944

HAMBURGER V (1960) A Manual of Experimental Embryology. Chicago: The University of Chicago Press. pp: 143-173

HAYASHIDA Y, KOYANO H, EYZAGUIRRE C (1980) An intracellular study of chemosensory fibers and endings. J Neurophysiol 44: 1077-88

LEMUS D, DABANCENS A, ILLANES J, FUENZALIDA M, GUERRERO A, LÓPEZ C (2001) Antiangiogenic effect of betamethasone on the chick cam stimulated by TA3 tumor supernatant. Biol Res 34: 227-36

LI BY, SCHILD JH (2002) Comparisons of somatic action potentials from dispersed and intact rat nodose ganglia using patch-clamp technique. Acta Pharmacol Sin 23: 481-9

LÓPEZ-BARNEO J, DEL TORO R, LEVITSKY KL, CHIARA MD, ORTEGA-SÁENZ P (2004) Regulation of oxygen sensing by ion channels. J Appl Physiol 96: 1187-95; discussion 1170-2

MOSQUEIRA M, VELÁSQUEZ L, ITURRIAGA R (2004) Gen pattern expression of carotid body under chronic hypoxia. Biol Res 37: R-107

NURSE CA, ZHANG M (2001) Synaptic mechanisms during re-innervation of rat arterial chemoreceptors in co-culture. Comp Biochem Physiol A Mol Integr Physiol 130: 241-51

PARDAL R, LÓPEZ-BARNEO J (2002) Carotid body thin slices: responses of glomus cells to hypoxia and $\mathrm{K}(+)$ channel blockers. Respir Physiol Neurobiol 132: 69-79

ROUS P, MURPHY JB (1911) Tumor implantations in the developing embryo. J Am Med Assoc 56: 741-742

SCHILD JH, CLARK JW, HAY M, MENDELOWITZ D, ANDRESEN MC, KUNZE DL (1994) A- and C-type rat nodose sensory neurons: Model interpretations of dynamic discharge characteristics. J Neurophysiol 71: 2338-58

SCHILD JH, KUNZE DL (1997) Experimental and modeling study of $\mathrm{Na}+$ current heterogeneity in rat nodose neurons and its impact on neuronal discharge. $\mathrm{J}$ Neurophysiol 78: 3198-209

VALDÉS V, VARAS R, ITURRIAGA R and ALCAYAGA $J$ (2004) Characterization of nicotine receptors in cultured cat petrosal ganglion neurons. Biol Res 37: R54.

ZAPATA P, LARRAÍN C (2005) How the carotid body works: Different strategies and preparations to solve different problems. Biol Res 38: 315-328 